\title{
CHARACTERIZATION OF HLA-DRB1 ALLELES POLYMORPHISMS IN PLASMODIUM FALCIPARUM MALARIA INFECTIONS IN JAZAN, KSA
}

\author{
By \\ WAFAA M. ZAKI ${ }^{1,2^{*}}$, HANAN Z. RAYAN ${ }^{1,2}$, AYMEN M. MADKHALY ${ }^{2}$ \\ AND KHAWLAA M. MADKHALY ${ }^{2}$
}

Department of Medical Parasitology, Faculty of Medicine, Suez Canal University, Ismalia, Egypt ${ }^{1}$ and Department of Medical Laboratory Technology, Faculty of Applied Medical Sciences, Jazan University Jazan, Kingdom of Saudi Arabia ${ }^{2}$

( ${ }^{\star}$ Correspondence: Wafaa_Zaki@hotmail.com)

\section{Abstract}

Malaria is a public health problem in the KSA. It is restricted to the southwestern region, where $P$. falciparum is the most prevalent species. The immune response which affects the clinical outcome of malaria is genetically controlled and is influenced with high degree of HLA genetic polymorphism. The present study aimed at assessing the relationship between HLA-DRB1 alleles and malaria susceptibility pattern moreover its degree of severity in a group of Saudi population in Jazan, KSA. A total of 60 malaria cases (51 uncomplicated and 9 severe malaria cases) and 60 control subjects were enrolled in this study. Blood samples were collected and genotyping of the HLA-DRB1 alleles was performed. The results suggested significant associations of HLA-DRB $1 * 04$ and HLA-DRB $1 * 11$ with susceptibility to malaria ( $p=0.002$ and $p=0.043$, respectively) and association of HLA-DRB ${ }^{*} 13$ with resistance to malaria $(p=0.032)$. The HLA-DRB $1 * 04$ was found to be associated with severe malaria.

The individuals with HLA-DRB $1 * 04$ and HLA-DRB $1 * 11$ were at increased risk to malaria infection and the HLA-DRB1* 04 carriers are more susceptible to severe malaria. While, HLA-DRB1* 13 carriers are more resistant to this infection. Wide investigations for this association may lead to implementation of a successful effective malaria vaccine program.

Key words; Saudi Arabia, Plasmodium falciparum, HLA-Drb1 Alleles Polymorphisms

\section{Introduction}

Malaria is one of the most prevalent endemic diseases worldwide (Autino et al, 2012). It has been a life-threatening illness in many countries for thousands of years, and has long been a challenge to be eradicated all over the world (Bawah and Binka, 2007). Almost half of the total world population is exposed to the risk of contracting malaria (Dalrymple et al, 2015). In 2016, an estimation of 216 million cases of malaria associated with 445000 deaths was reported (WHO, 2017).

In Saudi Arabia, about $5 \%$ of the national population (1.04 million people) is at risk of infection. Malaria occurs at hypo-to hyper perendimic level where $P$. falciparum was the commonest parasite that accounts for over $87 \%$ of malaria cases in Saudi Arabia (Alzahrani et al, 2017). However, the implementation of extensive control programs made it highly restricted to the Southwestern region. Jazan that is located in the Southwestern area and bordering Yemen (the most malarious regional country), estimated to be responsible for most locally acquired malaria cases recorded in Saudi Arabia (Bin Dajem and Al-Qahtani, 2010). More than 70\% of total national case burden occurred mainly Jazan and Asir (Snow et al, 2013). The average annual incidence of $0.3 / 10,000$ of the population was reported in Jazan through 2010-2014 (El Hassan et al, 2015). Meanwhile, the highest percentage of chloroquine resistant $P$. falciparum malaria was reported in Yemen which borders Saudi Arabia (AlMaktari and Bassiouny, 2003).

Plasmodium spp. leads to diverse clinical manifestations ranging from asymptomatic to severe complicated malaria (Bartoloni and Zammarchi, 2012). This wide spectrum of clinical presentation relay to a large extent on the underlying pathophysiological mechanism that differ from person to person, by presence in the same epidemiological circumstances which indicate different immune reactivity to malaria (Lima-Junior and Pratt-Riccio, 2016). In P. falciparum 
endemic areas, severe malaria is commonly found in children aged 5 years or less, while gaining partial immunity in older children and adults make the disease less severe. In areas with low endemicity, the age distribution of severe malaria is not well demarcated and may also occur in adult semi-immune persons (Bartoloni and Zammarchi, 2012). Several factors control malaria infection tendency (Belachew, 2018). One of the most important of these factors is the possible relationship between malaria and Human Leukocyte Antigen (HLA) gene variations that lead to a wide variability in immune reactivity (Driss et al, 2011). Utilization of HLA genes as a marker in malaria pathogenesis is substantially highlighted playing a crucial role in host-pathogen interaction (LimaJunior and Pratt-Riccio, 2016). HLA system is divided into three classes: class I: the classical HLA genes (HLA-A, -B \& -C), class II: the immune response genes; HLA-DR, DQ, and -DP, each of them has A \& B subunit and class III genes are for complement components (C2, C4, factor B), 21-hydroxylase, tumor necrosis factors (TNFs), \& other immune variants (Choo, 2007). In Class II, most variability comes from HLA-DRB, with >700 known alleles, but only three HLA-DRA variants are present (Driss et al, 2011). The relationship between class I and class II HLA alleles and malaria infection has been widely investigated; interestingly, this relationship was studied for both withincountries level (intra-countries) and between countries level (inter-countries) with more expressive results for between countries level (Garamszegi, 2014). eg. In an Indian case control study, a group of alleles: A3, B27, B49, DRB1*04, and DRB1*0809 showed increased incidence of malaria, while A19, A34, B18, B37, \& DQB1*0203 showed decreased incidence. HLA B49 \& DRB $1 * 0809$ were associated with the complicated severe form. HLA A19, B5 and B13 were protective in high parasite index patients (Shankarkumar et al, 2002).

But, in West Africa, some alleles were ass- ociated with the sever malaria resistance: B*53:01, DQB1*05:01, DRB1*13:02 (Hill et al, 1991), or associated with susceptibility to sever malaria: DRB1*04:01 (May et al, 1999). In this concern ethnic background must be taken into consideration while developing an ideal malaria vaccine (Shankarkumar et al, 2002). Wide investigations for this association may lead to implementation of a successful effective malaria vaccine program (Kwiatkowski, 2005).

This study aimed to assess the relationship between HLA-DRB1 alleles and malaria susceptibility pattern and its degree of severity in a group of Saudi population in Jazan, Kingdom of Saudi Arabia.

\section{Subjects and Methods}

Patients and controls: Through a case control study, two groups of subjects were selected 60 subjects each. Malaria cases group were selected from patients referred to Prince Mohamed Bin Naser, Sabia, AboErish and El-Ardaa general hospitals. They were 37 males and 23 females with positive diagnosis for Plasmodium falciparum they were selected from September 2015 to September 2018. Malaria diagnosis was based on clinical symptoms, the rapid diagnostic antigen detection OptiMal test (ICT-Amrad, Sydney, Australia) and examination of Giemsa stained thin \& thick blood films. Parasitaemia levels were calculated against WBCs and expressed as number of parasites/ $\mu 1$. Control group included 60 Saudi healthy individuals age and sex matched to cases without present or past history of malaria.

Malaria was classified into uncomplicated malaria and severe malaria (Bartoloni and Zammarchi, 2012), as follows: a- Uncomplicated malaria: Pyrexia, flu-like illness, myalgia, arthralgia, lassitude, headache, anorexia, vomiting, abdominal pain, lower back pain, tachycardia, and b- Severe malaria: The presence of one or more of the following manifestations is sufficient for a diagnosis of severe malaria: Impaired consciousness/coma, convulsions, hypoglycae- 
mia, severe normocytic anaemia, metabolic acidosis, coagulopathy with DIC, hyperparasitaemia $>5 \%$, pulmonary oedema, ARDS, acute renal failure, haemoglobinuria, circulatory shock, splenic rupture.

The patients and controls were included in after informed with the aim of the study and an accepted written consent was obtained from each one. The study was approved by the Scientific Research Ethics Committee (No. REC 39/4FS001) Jazan University.

Blood samples collection and DNA extraction: Peripheral blood samples were obtained from patients and controls in EDTA sterile vacutainers. DNA extraction and purification were performed from the whole blood samples using G-spin ${ }^{\mathrm{TM}}$ total DNA extraction kit (iNtRON Biotechnology) following the manufacturer's instructions. DNA concentrations were obtained using the NanoDrop One/One ${ }^{\mathrm{c}}$ spectrophotometer (Thermo Fisher Scientific) and content measured between $0.02 \& 0.04 \mu \mathrm{g} / \mu \mathrm{l}$ was used for HLA-DRB1 amplification by PCR.

HLA-DRB 1 alleles genotyping: Genotyping of HLA-DRB1 alleles was done using the INNO-LiPA HLA-DRB1 Plus (Fujirebio, Germany $\mathrm{GmbH}$ ) following the maufacturer's instructions.

The test was based on the reverse hybridization principle and the following steps were involved: Step 1: Amplification of exon 2 of

Table 1: Characteristics of the malaria
HLA-DRB1 alleles. Step 2: Hybridization and stringent wash with 37 probes immobilized on one INNO-LiPA HLA-DRB1 Plus strip $\left(56^{\circ} \mathrm{C}\right)$. Step 3: Color development. Step 4: Interpretation of the probe reactivity pattern using the LiRAS interpretation software.

Statistical analysis: Data were analyzed using SPSS v16 (SPSS Inc, Chicago, USA). Different HLA-DRB1 allele frequencies were compared between pairs of malaria groups to assess association of different alleles with disease susceptibility or resistance by using Chi-square $(\chi 2)$ test based on a $2 \times 2$ contingency table. $\mathrm{P}$ value was considered significant at $\mathrm{P} \leq 0.05$.

\section{Results}

In the present study 120 Saudi subjects (60 malaria patients and 60 healthy controls) were tested for HLA-DRB1 alleles frequency. The demographic characteristics of malaria cases were shown with a mean age \pm (SD) $33 \pm 9$ years (Bartoloni and Zammarchi, 2012), malaria cases were grouped into 51 uncomplicated malaria cases and 9 severe malaria cases.

The most frequent severe malaria cases occurred in age group $\leq$ five years (4 cases) and to a lesser degree for cases more than 55 years ( 2 cases), malaria infection was prevalent in males more than females $(37,62 \%$ vs. $23,38 \%$ ).

\begin{tabular}{|c|c|c|c|}
\hline Table 1: Characteristics of the malaria cases group in relation to malaria severity. \\
\begin{tabular}{|c|c|c|c|}
\hline Character & Uncomplicated malaria $(\mathrm{n}=51)$ & Sever malaria $(\mathrm{n}=9)$ & Total $(\mathrm{n}=60)$ \\
\hline Age group: & 7 & 4 & 11 \\
\hline$\leq 5$ Years & 6 & 1 & 7 \\
\hline$>5-15$ & 4 & 1 & 4 \\
\hline $15-25$ & 7 & 0 & 8 \\
\hline $25-35$ & 9 & 1 & 11 \\
\hline $35-45$ & 10 & 2 & 10 \\
\hline $45-55$ & 8 & & 37 \\
\hline$>55$ years & & 5 & 23 \\
\hline Sex: & 32 & 4 & 60 \\
\hline Male & 19 & 9 & 9 \\
\hline Female & 51 & & \\
\hline Total & & & \\
\hline
\end{tabular}
\end{tabular}

HLA-DRB1 alleles frequencies in patients and controls: 12 alleles were detected in them, the commonest frequent allele in patients was HLA-DRB $1 * 04$, with frequency of $28 \%$ and the commonest one in controls was HLA-DRB1 ${ }^{*} 13$ with frequency of $22 \%$, frequency of $3 \%$ was the least frequency detected as it was found in patients for allele 
HLA-DRB $1 * 08$ and in controls for alleles HLA-DRB $1 * 07$ and HLA-DRB1*11.

Significant difference was between pa

Table 2: Distribution of HLA-DRB1 alleles in malaria cases and controls

\begin{tabular}{|c|c|c|c|c|c|c|c|c|}
\hline \multirow[t]{2}{*}{ HLA-DRB1 allele } & \multicolumn{2}{|c|}{ Malaria cases } & \multicolumn{2}{|c|}{ Control } & \multirow[t]{2}{*}{ Chi square } & \multirow[t]{2}{*}{$\mathrm{P}$ value $^{\mathrm{a}}$} & \multirow[t]{2}{*}{$95 \% \mathrm{CI}$} & \multirow[t]{2}{*}{ OR } \\
\hline & No. & $\%$ & No. & $\%$ & & & & \\
\hline \multicolumn{9}{|l|}{ HLA DRB $1 * 03$} \\
\hline Positive & 11 & 18 & 6 & 10 & 1.581 & \multirow[t]{2}{*}{0.208} & \multirow[t]{2}{*}{4.73 to 20.71} & \multirow[t]{2}{*}{2.020} \\
\hline Negative & 49 & 82 & 54 & 90 & & & & \\
\hline \multicolumn{9}{|l|}{ HLA DRB $1 * 04$} \\
\hline Positive & 17 & 28 & 4 & 7 & 9.087 & \multirow[t]{2}{*}{$0.002^{\mathrm{a}}$} & \multirow[t]{2}{*}{7.47 to 34.1} & \multirow[t]{2}{*}{5.534} \\
\hline Negative & 43 & 72 & 56 & 93 & & & & \\
\hline \multicolumn{9}{|l|}{ HLA DRB $1 * 07$} \\
\hline Positive & 3 & 5 & 2 & 3 & 0.310 & \multirow[t]{2}{*}{0.577} & \multirow[t]{2}{*}{6.54 to 10.98} & \multirow[t]{2}{*}{1.526} \\
\hline Negative & 57 & 95 & 58 & 97 & & & & \\
\hline \multicolumn{9}{|l|}{ HLA DRB $1 * 08$} \\
\hline Positive & 2 & 3 & 4 & 7 & 1.002 & \multirow[t]{2}{*}{0.316} & \multirow[t]{2}{*}{4.92 to 13.62} & \multirow[t]{2}{*}{0.482} \\
\hline Negative & 58 & 97 & 56 & 93 & & & & \\
\hline \multicolumn{9}{|l|}{ HLA DRB $1 * 09$} \\
\hline Positive & 7 & 12 & 9 & 15 & 0.229 & \multirow[t]{2}{*}{0.632} & \multirow[t]{2}{*}{9.63 to 15.63} & 0.748 \\
\hline Negative & 53 & 88 & 51 & 85 & & & & \\
\hline HLA DRB $1 * 10$ & & & & & & & & \\
\hline Positive & 8 & 13 & 5 & 8 & 0.791 & 0.373 & 6.53 to 16.71 & 1.692 \\
\hline Negative & 52 & 97 & 55 & 92 & & & & \\
\hline HLA DRB $1 * 11$ & & & & & & & & \\
\hline Positive & 9 & 15 & 2 & 3 & 5.231 & $0.022^{a}$ & 1.52 to 23.33 & 5.117 \\
\hline Negative & 51 & 85 & 58 & 97 & & & & \\
\hline HLA DRB $1 * 12$ & & & & & & & & \\
\hline Positive & 6 & 10 & 8 & 13 & 0.26 & 0.608 & 8.96 to 15.02 & 0.722 \\
\hline Negative & 54 & 90 & 52 & 87 & & & & \\
\hline HLA DRB $1 * 13$ & & & & & & & & \\
\hline Positive & 5 & 8 & 13 & 22 & 4.573 & $0.032^{\mathrm{a}}$ & 1.06 to 26.83 & 0.293 \\
\hline Negative & 55 & 92 & 46 & 77 & & & & \\
\hline HLA DRB $1 * 14$ & & & & & & & & \\
\hline Positive & 9 & 15 & 7 & 12 & 0.229 & 0.632 & 9.63 to 15.63 & 1.336 \\
\hline Negative & 51 & 85 & 53 & 88 & & & & \\
\hline HLA DRB $1 * 15$ & & & & & & & & \\
\hline Positive & 7 & 12 & 4 & 7 & 0.865 & 0.352 & 6.12 to 16.37 & 1.849 \\
\hline Negative & 53 & 88 & 56 & 93 & & & & \\
\hline HLA DRB $1 * 16$ & & & & & & & & \\
\hline Positive & 5 & 8 & 9 & 15 & 1.432 & 0.231 & 4.86 to 19.03 & 0.515 \\
\hline Negative & 55 & 92 & 51 & 85 & & & & \\
\hline
\end{tabular}

${ }^{a}$ Significant at $\mathrm{p} \leq 0.05$, CI: confidence interval, OR: odds ratio. Only alleles with frequency shown

According to malaria severity (Table 3 ) one allele HLA-DRB $1{ }^{*} 04$ showed signifi- tients and control in alleles HLA-DRB $1 * 04$, HLA-DRB $1 * 11$ and HLA-DRB $1 * 13$. P= $0.002,0.043 \& 0.032$ respectively (Tab. 2 ). 
Table 3: Association of HLA-DRB1 alleles with malaria severity.

\begin{tabular}{|c|c|c|c|c|c|}
\hline \multirow{2}{*}{$\begin{array}{l}\text { Malaria severity } \\
\text { HLA-DRB1 allele }\end{array}$} & \multicolumn{2}{|c|}{ Uncomplicated malaria (51) } & \multicolumn{2}{|c|}{ Severe malaria (9) } & \multirow{2}{*}{$\mathrm{P}_{\text {value }}{ }^{\mathrm{a}}$} \\
\hline & No. & $\%$ & No. & $\%$ & \\
\hline \multicolumn{6}{|l|}{ HLA DRB $1 * 03$} \\
\hline Positive & 8 & 16 & 3 & 33 & 0.230 \\
\hline Negative & 43 & 84 & 6 & 67 & \\
\hline \multicolumn{6}{|l|}{ HLA DRB $1 * 04$} \\
\hline Positive & 11 & 22 & 6 & 67 & $0.006^{\mathrm{a}}$ \\
\hline Negative & 40 & 78 & 3 & 33 & \\
\hline \multicolumn{6}{|l|}{ HLA DRB $1 * 07$} \\
\hline Positive & 3 & 6 & 0 & 0 & 0.454 \\
\hline Negative & 48 & 94 & 9 & 100 & \\
\hline \multicolumn{6}{|l|}{ HLA DRB $1 * 08$} \\
\hline Positive & 1 & 2 & 1 & 11 & 0.170 \\
\hline Negative & 50 & 98 & 8 & 89 & \\
\hline \multicolumn{6}{|l|}{ HLA DRB $1 * 09$} \\
\hline Positive & 5 & 10 & 2 & 22 & 0.307 \\
\hline Negative & 46 & 90 & 7 & 78 & \\
\hline \multicolumn{6}{|l|}{ HLA DRB $1 * 10$} \\
\hline Positive & 6 & 12 & 2 & 22 & 0.422 \\
\hline Negative & 45 & 88 & 7 & 78 & \\
\hline \multicolumn{6}{|l|}{ HLA DRB $1 * 11$} \\
\hline Positive & 8 & 16 & 1 & 11 & 0.702 \\
\hline Negative & 43 & 84 & 8 & 89 & \\
\hline \multicolumn{5}{|l|}{ HLA DRB $1 * 12$} & \multirow{3}{*}{0.202} \\
\hline Positive & 4 & 8 & 2 & 22 & \\
\hline Negative & 47 & 92 & 7 & 78 & \\
\hline \multicolumn{6}{|l|}{ HLA DRB $1 * 13$} \\
\hline Positive & 3 & 6 & 2 & 22 & 0.113 \\
\hline Negative & 48 & 94 & 7 & 78 & \\
\hline \multicolumn{6}{|l|}{ HLA DRB $1 * 14$} \\
\hline Positive & 6 & 12 & 3 & 33 & 0.108 \\
\hline Negative & 45 & 88 & 6 & 67 & \\
\hline \multicolumn{6}{|l|}{ HLA DRB $1 * 15$} \\
\hline Positive & 6 & 12 & 2 & 22 & 0.422 \\
\hline Negative & 45 & 88 & 7 & 78 & \\
\hline \multicolumn{6}{|l|}{ HLA DRB $1 * 16$} \\
\hline Positive & 4 & 8 & 1 & 11 & 0.767 \\
\hline Negative & 47 & 92 & 8 & 89 & \\
\hline
\end{tabular}

${ }^{\mathrm{a}}$ Significant at $\mathrm{p} \leq 0.05$, HLA-DRB1 alleles showed significant difference between male $\&$ female for HLA-DRB $1 * 13$ $(\mathrm{P}=0.05)$. No significant difference between male and female for both HLA DRB1*04 \& HLA-DRB1* 11.

Table 4: Association between gender and significant HLA DRB1 alleles.

\begin{tabular}{|c|c|c|c|c|c|}
\hline HLA DRB1 significant alleles & Male $(n=37)$ & $\%$ & Female $(n=23)$ & $\%$ & $P$ value \\
\hline \multicolumn{6}{|l|}{ HLA DRB $1 * 04$} \\
\hline Positive & 9 & 24 & 8 & 35 & \multirow[t]{2}{*}{0.36} \\
\hline Negative & 28 & 76 & 15 & 65 & \\
\hline \multicolumn{6}{|l|}{ HLA DRB $1 * 11$} \\
\hline Positive & 4 & 11 & 5 & 22 & \multirow[t]{2}{*}{0.25} \\
\hline Negative & 33 & 89 & 18 & 78 & \\
\hline \multicolumn{6}{|l|}{ HLA DRB $1 * 13$} \\
\hline Positive & 1 & 3 & 4 & 17 & $0.05^{\mathrm{a}}$ \\
\hline Negative & 36 & 97 & 19 & 83 & \\
\hline
\end{tabular}

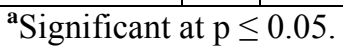




\section{Discussion}

The association between specific HLA alleles and susceptibility or resistance to $P$. falciparum malaria was previously investigated in several studies among different ethnic groups. Although several associations have been reported yet, no associations have been confirmed in different populations (May et al, 1999; Driss et al, 2011; Mosaad, 2015). The present study results revealed significant associations between malaria infection and a number of HLA- DRB1 alleles, HLA- DRB1*04 \& DRB1*11 were associated with susceptibility to infection while DRB1*13 was associated with resistance. Only HLA DRB1* 04 allele was found to be associated with severe malaria.

Studies in other ethnic groups showed different allelic distributions and associations between HLA and malaria. Results from Gabon and Ghana suggested that HLADRB1*04 was associated both with susceptibility to malaria in general and an increased risk of severe malaria (Osafo-Addo et al, 2008; May et al, 1999). While in Senegal, The most frequent HLA-DR alleles found in malaria patients were: DR52, DR13, DR10, DR53, DR3 \& DR18. A significant difference occurred between patients with severe malaria and the control group of the following alleles: DR3, DR10, DR13. HLA-DR3 was considered as the major marker associated to severe malaria (Ndiaye et al, 1998). In Mumbai, western India, the frequency of DRB1*04, \& DRB1*0809 were significantly increased in patients with malaria compared to controls. DRB $1 * 0809$ was found to be positively associated with the complicated severe malaria (Shankarkumar et al, 2002). Another study in Thai malaria patients showed a significant difference in distribution of HLA-B46, -B56 \& DRBI* 10:01 between malaria groups; mild malaria, non-cerebral severe malaria and cerebral malaria groups. DRB1*10:01 was significantly increased in mild malaria group compared to non-cerebral severe malaria (Hananantachai et al, 2005). On the other hand,
Carpenter et al. (2009) in Tanzania studied the genetics of susceptibility to malaria related phenotypes population and concluded weak associations between HLA-DRB $1 * 04$ and HLA-DRB $1 * 10$ with parasite density.

In the present study, HLA-DRB $1 * 11$ was associated with malaria infection. Although it was not reported previously to be associated with malaria, it was reported to be associated with other diseases. Associations were reported between HLA-DRB $1 * 11$ and persistence of hepatitis B virus infection (Thio et al, 1999); Mite sensitive asthma (Lara-Marquez et al, 1999); juvenile rheumatoid arthritis (Garavito et al, 2004) and systemic sclerosis (Kuwana et al, 1999).

In the present study, HLA-DRB1*13 was associated with reduced susceptibility to malarial infection as the difference between patients and control was statistically significant. In agreement with this result, Hill et al. (1991) found that HLA-DRB1*1302, $\mathrm{B}^{*}$ 53:01 \& $\mathrm{DQB} 1 * 05: 01$ were associated with resistance to severe malaria in a casecontrol study of severe malaria in children in Gambia. However, May et al. (1999) failed to observe protective effect of DRB $1 * 1302$ in a group of patients in Gabon. While in Western Kenya, an association between HLA DRB $1 * 0101$ and resistance to severe malaria was reported (Hill, 1998). Others suggested that HLA DQB $1 * 0203$ was associated with decreased risk of malaria infection (Shankarkumar et al, 2002).

On the other hand, Lyke et al. (2011) observed that the allele frequency distribution of HLA-A differed significantly between patients with cerebral and uncomplicated malaria, whereas there was no significant difference found for HLA-B, -C nor -DRB1 in a population of Malian children. Moreover, in Gambia no association was between HLA \& frequency of clinical episodes of malaria (Bennett et al, 1993). The differences observed in the present study results compared to other studies could be due, in part, to variation in allele frequencies and the geographic variation in the genetic 
makeup of different ethnic groups (Torcia et $a l$, 2008; Ockenhouse et al, 2006). This genetic diversity has been shown to contribute to differences in immune response to diseases or disease outcomes (Ockenhouse et al, 2006). Also, numerous factors are thought to be responsible for the emergence of different dominant HLA antigens in different endemic populations. Such factors include micro heterogeneity in parasite species, wide genetic variability in parasitic antigens, transmission intensity fluctuations, different polymorphisms of red cell antigens, and selection pressure that have been exerted by diversity in the HLA system (Hedrick, 2011).

The mechanism associating HLA-DRB1 alleles with susceptibility or resistance to malaria was studied by several researchers. In this respect, the antigen presentation of MHC class I proteins, by triggering cytotoxic $\mathrm{T}$ cells against intracellular parasites, may play an important role during the liver-stage infection, while class II molecules can mediate the clearance of parasitized erythrocytes from bloodstream through the stimulation of helper $\mathrm{T}$ cells by providing help for $B$ cell differentiation and secretion of antibodies (Wijayalath et al, 2014). The CD4+ $\mathrm{T}$ cells also restrict growth of erythrocyte Plasmodium parasites through cytokine secretion and macrophage activation (Tsuji, 2010). Nardin et al. (2000) found higher anti-sporozoite antibodies titers associated with HLA-DR5 (DRB1*1101) plus DRB1* 0401 and DQB $1 * 0603$ in a clinical trial of Multiple Antigens Peptides (MAP) vaccine. Storti-Melo et al. (2012) found an association between HLA-DR3 \& HLA-DR5 alleles and lack of antibody response to CSP (Circum Sporozoite Protien) amino terminal, as well as an association between HLA-DR3 and the highest antibody res- ponse to MSP1 ( Merozoite Surface Protien 1) in Brazilian population exposed to malaria. Lima-Junior et al. (2012) found high frequency of responders to carboxy-terminal (CT) and aminoterminal (NT) regions of MSP-3 in HLADRB1*04 carriers. Presence of HLA-DRB1
*04 was positively associated with the IgG immune response against the amino-terminal domain (NT) and the C-terminal blocks of tandem repeats (RII \& RIRII) of MSP-9. Wijayalath et al. (2014) proved that HLADR0402, HLA-DQ6, HLA-DQ8, and to less extent, HLA-DR0301 molecules sufficed for supporting antibody responses and selfcuring of Plasmodium yoelii strain 17XNL malaria infection, while HLA-DR0401 molecules failed to do so.

For the current study, HLA-DRB $1 * 13$ that was associated with reduced susceptibility to malaria, was found more prevalent in females than males in a significant difference. Akanbi et al. (2010) in Nigeria concluded that the mean malaria parasite density was higher in male than in female patients. Sex differences in immune status and immune response to parasites were widely studied in vertebrates (Klein et al, 2004) It was reported that females had higher imm- une responses than males conspecifics parti- cularly, innate immune responses, antibodymediated responses, and cellular responses (Roberts et al, 2001). Also, the antigenpresenting cells (APC) of female mice were more efficient at presenting peptides compared to male mice (Weinstein et al, 1984). Also, Klein et al. (2008) in vivo suggested that physiological levels of estrogen, rather than progesterone, enhanced immunity and, possibly, protected females from disease symptoms during malaria infection Also another study demonstrated that protection by vaccines developed against $P$. chabaudi in mice was greater for females than males and that elevated testosterone concentrations reduced the efficacy of vaccines against $P$. chabaudi (Wunderlich et al, 1993). Exposure of adult female mice to testosterone reduced the antibody production, decreased major histocompatibility complex (MHC) class II cells in spleen, and increased the CD8+ T-cells (Benten et al, 1997). Legorreta-Herrera et al. (2015) reported that in female mice, sex hormones have anti-inflammatory properties and sex hormones levels 
affect the immune response and must be considered when designing malaria vaccines.

\section{Conclusion}

The individuals with HLA DRB1* 04 and HLA DRB1* 11 are at increased risk to malaria infection moreover HLA DRB $1 * 04$ carriers are more susceptible to severe malaria. While, HLA DRB1* 13 carriers are more resistant to this infection. The disclosure of genetic markers associated with various malaria phenotypes will help clarify the pathophysiology of malaria and empower development of interventions and cures.

Author contribution: Wafaa M. Zaki proposed the research idea, the study design, contribution in sample collection, laboratory procedures, and prepared the final version for submission. Hanan Z. Ryan shared in the study design, sample collection, and revised the manuscript. Aymen M. Madkhaly was responsible for acquisition, analysis and interpretation of resulting data, Khawlaa M. Madkhaly contributed in sample collection and laboratory procedures, all authors revised manuscript and approved it.

Conflict of interest: The authors declare having no conflict of interest.

\section{Acknowledgment}

The authors would like to express their gratitude to the Deanship of Scientific Research, Jazan University, Jazan, KSA, for allowing and funding this study (number FS5-017).

\section{References}

Akanbi1, OM, Badaki1, JA, Adeniran, OY, Olotu OO, 2010: Effect of blood group and demographic characteristics on malaria infection, oxidative stress and haemoglobin levels in South Western Nigeria. Afr. J. Microbiol Res. 4, 9:877-80

Alzahrani, MH, McCall, P, Hassan, A, Omar, AI, Abdoon, AM, 2017: Impact of irrigation system on malaria transmission in Jazan Region, Saudi Arabia. Open J. Trop. Med. 1, 1:7-15.

Autino, B, Noris, A, Russo, R, Castelli, F, 2012: Epidemiology of malaria in endemic areas. Mediterranean J. Hematol. Infect. Dis. 4, 1: e 2012060.
Bartoloni, A, Zammarchi, L, 2012: Clinical aspects of uncomplicated \& severe malaria. Mediterr. J. Hematol. Infect. Dis. 4, 1: e2012026.

Bawah, AA, Binka, FN, 2007: How many years of life could be saved if malaria were eliminated from a hyperendemic area of northern Ghana? Am. J. Trop. Med. Hyg. 77, 6:S145-52. Belachew, EB, 2018: Immune response and evasion mechanisms of Plasmodium falciparum parasites. J. Immun. Res., Article ID652968.

Bennett, S, Allen, SJ, Olerup, O, Jackson, DJ, Wheeler, JG, et al, 1993: Human leucocyte antigen (HLA) and malaria morbidity in a Gambian community. Trans. R. Soc. Trop. Med. Hyg. 87, 3:286-7.

Benten, WP, Ulrich, P, Kuhn-Velten, WN, Vohr, HW, Wunder-lich F, 1997: Testosterone-induced susceptibility to Plasmodium chabaudi malaria: persistence after withdrawal of testosterone. J. Endocrinol. 153:275-81.

Bin Dajem, SM, Al-Qahtani, A, 2010: Analysis of gene mutations involved in chloroquine resistance in Plasmodium falciparum parasites isolated from patients in the southwest of Saudi Arabia. Ann. Saudi Med. 30:187-92

Carpenter, D, Rooth, I, Färnert, A, Abushama, H, Quinnell, RJ, et al, 2009: Genetics of susceptibility to malaria related phenotypes. Infect. Genet. Evol. 9, 1:97-103.

Choo, SY, 2007: The HLA system: Genetics, immunology, clinical testing, and clinical implications. Yonsei Med. J. 48, 1:11-23.

Dalrymple, U, Mappin, B, Gething, PW, 2015: Malaria mapping: understanding the global endemicity of falciparum and vivax malaria. BMC Med. 1213:140. doi: 10.1186/s12916-0150372-x.

Driss, A, Hibbert, JM, Wilson, NO, Iqbal, SA, Adamkiewicz, TV, et al, 2011: Genetic polymorphisms linked to susceptibility to malaria. Malar. J. 10:271-6.

El Hassan, IM, Sahly, A, Alzahrani, MH, Alhakeem, RF, Alhelal, M, et al, 2015: Progress toward malaria elimination in Jazan Province, Kingdom of Saudi Arabia: 2000-2014. Malar. J. 9, 14:444.

Garamszegi, LZ, 2014: Global distribution of malaria-resistant MHC-HLA alleles: the number and frequencies of alleles and malaria risk. Malar. J. 13:349. 
Garavito, G, Yunis, E, Egea, E, Ramirez, L, Malagón, C, et al, 2004: HLA-DRB1 alleles and HLA-DRB1 shared epitopes are markers for juvenile rheumatoid arthritis subgroups in Colombian Mestizos. Hum. Immunol. 65, 4:359-65.

Hananantachai, H1, Patarapotikul, J, Ohashi, J, Naka, I, Looareesuwan, S, et al, 2005: Polymorphisms of the HLA-B and HLA-DRB1 genes in Thai malaria patients. J. Infect. Dis. 58, 1:25-8.

Hedrick, PW, 2011: Population genetics of malaria resistance in humans. Heredity 107, 4:283304.

Hill, AV, 1998: The immunogenetics of human infectious diseases. Ann. Rev. Immunol. 16:593617.

Hill, AV, Allsopp, CE, Kwiatkowski, D, Anstey, NM, Twumasi P, et al, 1991: Common West African HLA antigens are associated with protection from severe malaria. Nature 352:595600

Klein, PW, Easterbrook, JD, Lalime, EN, KIein, SL, 2008: Estrogen and progesterone affect responses to malaria infection in female C57BL/ 6 mice. Gend. Med. 5, 4:423-33

Klein, SL, 2004: Hormonal and immunological mechanisms mediating sex differences in parasite infection. Parasite Immunol. 26:247-64

Kuwana, M, Kaburaki, J, Arnett, F, Howard, R, Medsger, T, et al, 1999: Influence of ethnic background on clinical and serologic features in patients with systemic sclerosis and anti-DNA topoisomerase I antibody. Arthritis Rheum. 42, 3:465-74.

Kwiatkowski, DP, 2005: How malaria has affected the human genome and what human genetics can teach us about malaria. Am. J. Hum. Genet. 77, 2:171-92.

Lara-Marquez, M, Yunis, J, Layrisse, Z, Ortega, F, Carvallo-Gil, E, et al, 1999: Immunogenetics of atopic asthma: association of DRB1 *1101 DQA1*0501 DQB1*0301 haplotype with Dermatophagoides spp.-sensitive asthma in a sample of the Venezuelan population. Clin. Exp. Allergy 29, 1:60-71.

Legorreta-Herrera, M, Mosqueda-Romo, NA, Nava-Castro, KE, Morales-Rodríguez, AL, Buendía-González, FO, et al, 2015: Sex hormones modulate the immune response to Plasmodium berghei ANKA in CBA/Ca mice. Parasitol. Res. 114, 7:2659-69.

Lima-Junior, JC, Pratt-Riccio, LR, 2016: Major histocompatibility Complex and Malaria:
Focus on Plasmodium vivax Infection. Front. Immunol. 7:13-8.

Lima-Junior, JC, Rodrigues-da-Silva, RN, Banic, DM, Jiang, J, Singh, B, et al, 2012: Influence of HLA-DRB1 and HLA-DQB1 alleles on IgG antibody response to the $P$. vivax MSP-1, MSP-3alpha and MSP-9 in individuals from Brazilian endemic area. PLoS One 7:e36419.

Lyke, KE, Fernández-Viňa, MA, Cao, K, Hollenbach, J, Coulibaly, D, et al, 2011: Association of HLA alleles with Plasmodium falciparum severity in Malian children. Tissue antigens.77, 6:562-71.

May, J, Meyer, CG, Kun, JF, Lell, B, Luckner, D, et al, 1999: HLA class II factors associated with Plasmodium falciparum merozoite surface antigen allele families. J. Infect. Dis. 179, 4: 1042-5.

Mosaad, YM, 2015: Clinical role of human leukocyte antigen in health and disease. Scand. J. Immunol. 82, 4:283-306.

Nardin, EH, Oliveira, GA, Calvo-Calle, JM, Castro, ZR, Nussenzweig, RS, et al, 2000: Synthetic malaria peptide vaccine elicits high levels of antibodies in vaccines of defined HLA genotypes. J. Infect. Dis. 182, 5:1486-96.

Ndiaye, M, Thiam, A, Ndiaye, R, Angel, G, Seignot, P, et al, 1998: Susceptibility to neuromalaria and HLA-DR alleles in Senegal. Dakar Med. 43, 1:25-8.

Ockenhouse, CF, Hu, WC, Kester, KE, Cummings, JF, Stewart, A, et al, 2006: Common and divergent immune response signaling pathways discovered in peripheral blood mononuclear cell gene expression patterns in presymptomatic and clinically apparent malaria. Infect. Immun. 74, 10:5561-73.

Osafo-Addo, AD, Koram, KA, Oduro, AR, Wilson, M, Hodgson, A, et al, 2008: HLADRB $1 * 04$ allele is associated with severe malaria in northern Ghana. Am. J. Trop. Med. Hyg. 78, 2:251-5.

Roberts, CW, Walker, W, Alexander, J, 2001: Sex-associated hormones and immunity to protozoan parasites. Clin. Microbiol. Rev. 14, 3: 476-88.

Shankarkumar U, Devaraj JP, Ghosh K, Ka$\operatorname{rnad} \mathrm{D}$, Anand K, et al, 2002: HLA associations in $P$. falciparum malaria patients from $\mathrm{Mu}-$ mbai, western India. Indian J. Malariol. 39, 3/4: 76-82.

Snow, RW, Amratia, P, Zamani, G, Mundia, CW, Noor, AM, et al, 2013: The malaria transi- 
tion on the Arabian Peninsula: progress toward a malaria-free region between 1960-2010. Adv. Parasitol. 82:205-51.

Storti-Melo, LM, da Costa, DR, Souza-Neiras, WC, Cassino, GC, Couto, VS, et al, 2012:

Influence of HLA-DRB-1 alleles on the production of antibody against CSP, MSP-1, AMA-1, and DBP in Brazilian individuals naturally infected with Plasmodium vivax. Acta Trop. 121: 152-5.

Thio, C, Carrington, M, Marti, D, O'Brien, S, Vlahov, D, et al, 1999: Class II HLA alleles and hepatitis B virus persistence in African Americans. J. Infect. Dis. 179, 4:1004-6.

Torcia, MG, Santarlasci, V, Cosmi, L, Clemente, A, Maggi, L, et al, 2008: Functional deficit of $\mathrm{T}$ regulatory cells in Fulani, an ethnic group with low susceptibility to Plasmodium falciparum malaria. Proc. Nat. Acad. Sci. USA. 105, 2:646-51.

Tsuji, M, 2010: A retrospective evaluation of the role of $\mathrm{T}$ cells in the development of malaria vaccine. Exp. Parasitol. 126, 3:421-5.
Weinstein Y, Ran, S, Segal, S, 1984: Sex-associated differences in the regulation of immune responses controlled by the MHC of the mouse. J. Immunol. 132: 656-61.

WHO, 2017: World Malaria Report 2017. Geneva: http: //www.who.int/malaria/ publications/ world-malaria-report-2016/en.

Wijayalath, W, Majji, S, Villasante, EF, Brumeanu, TD, Richie, TL, et al, 2014: Humanized HLA-DR4. RagKO.IL2 R $\gamma$ cKO.NOD (DRAG) mice sustain the complex vertebrate life cycle of Plasmodium falciparum malaria. Malar. J. 30, 13:386-9.

Wunderlich, F, Maurin, W, Benten, WP, Scmitt-Wrede, HP, 1993: Testosterone impairs efficacy of protective vaccination against $P$. chabaudi malaria. Vaccine 11:1097-99

Al-Maktari, MT, Bassiouny, HK, 2003: Malaria status in Al-Hodeidah Governorate, Republic of Yemen. Part II: Human factors causing the persistence of chloroquine resistant $\mathrm{P}$. falciparum local strain. J. Egypt. Soc. Parasitol. 33, 3:829-39. 